ISSN 0103-8478

\title{
Anatomia foliar de três espécies de Stylosanthes SW. e sua associação com a composição e formação potencial de fitobezoares em bovinos
}

\author{
Leaf anatomy of three species of Stylosanthes SW. and its association \\ with the composition and formation potencial of phytobezoar in bovines
}

\author{
Diogo da Silva Matos ${ }^{\mathrm{I}}$ Flávia Maria Leme $^{\mathrm{I}}$ Edna Scremin Dias $^{\mathrm{I}}$ \\ Rosani do Carmo de Oliveira Arruda ${ }^{\mathrm{I}}$
}

\section{RESUMO}

Fitobezoares são estruturas formadas pela agregação de fibras, principalmente vegetais, no trato digestivo de ruminantes, ocasionando obstruções intestinais que podem levar o animal à morte. Informações sobre a formação desse aglomerado ainda são escassas. Neste estudo, são identificados os principais componentes de fitobezoares bovinos, e descrita as estruturas anatômicas das folhas de três espécies de Stylosanthes SW.: S.capitata Vogel, S. macrocephala M. B. Ferreira \& S. Costa, S. guianensis var. vulgaris M.B. Ferreira \& Sousa Costa cv. 'Mineirão' e S. guianensis (Aubl.) Sw. As plantas selecionadas são utilizadas na dieta do gado e potenciais formadoras do fitobezoar. Os fitobezoares foram fragmentados para análise de sua composição e analisados seguindo-se as técnicas da anatomia vegetal. As fibras e cristais encontrados em fitobezoares são similares aos observados nos feixes esclerenquimáticos presentes nos folíolos das espécies de Stylosanthes avaliadas. Nossos resultados apontam diferenças na abundância de fibras nos folíolos de cada espécie. S. macrocephala é a variedade que sugere maior potencial para formação de fitobezoares no trato digestivo de animais que se alimentam dessa leguminosa, devido a abundância de fibras e cristais presentes na folha. Os feixes esclerenquimáticos, idioblastos e a abundância de cristais de oxalato de cálcio nas espécies Stylosanthes podem potencializar a formação de fitobezoares em ruminantes, em especial quando essas leguminosas são consumidas em excesso.

Palavras-chave: obstrução intestinal, fibras, leguminosas, Stylosanthes.

\section{ABSTRACT}

Phytobezoars are structures formed by the aggregation of primarily plant fibers in the digestive tract of ruminants, causing intestinal obstruction that can lead to the death of an animal. Information about the formation of these clusters is scarce. This study identified the main components of bovine phytobezoars and described the leaf anatomy of three species and one variety of Stylosanthes SW.: S.capitata Vogel, S. macrocephala B. Ferreira \& S. Costa, S. guianensis var. vulgaris M.B. \& Sousa Ferreira Costa cv. 'Mineirão' and S. guianensis (Aubl.) Sw. These plants are used as feed for livestock and probably contribute to the formation of phytobezoars. The phytobezoars were fragmented for analysis of their internal composition and were studied according to plant anatomy techniques. The fibers and crystals found in phytobezoars were similar to the sclerenchyma fiber bundles found in Stylosanthes. The comparative analysis of Stylosanthes showed differences in the abundance of fibers in the leaflets of each species. S. macrocephala is the variety that may have the highest potential for formation of phytobezoars in the digestive tract of animals because there was an abundance of fibers and crystals present in the leaf. The sclerenchyma bundles, idioblasts, and the abundance of calcium oxalate crystals in Stylosanthes species may potentiate the formation of phytobezoars in ruminants, particularly when these legumes are consumed in excess.

Key words: intestinal obstruction, fibers, legumes, Stylosanthes.

\section{INTRODUÇÃO}

Os bezoares são corpos estranhos formados por agregação, geralmente, de compostos alimentares e/ou pelos de animais, sendo comum a presença de materiais vegetais, que podem estar envolvidos por material viscoso, conferindo muita resistência ao aglomerado (POZO \& VALOIS, 1996). Os bezoares podem ser formados em sua maior parte por fibras vegetais (fitobezoares), por cabelos (tricobezoares) (MORAES et al., 1993) ou por minerais (litozoários) (MARTINS et al., 2004). Pouco se conhece sobre a formação dos fitobezoares e, aparentemente, eles ocorrem devido a fatores relativos à mastigação

'Laboratório de Botânica, Centro de Ciências Biológicas e da Saúde (CCBS), Universidade Federal do Mato Grosso do Sul (UFMS), 79070-900, Campo Grande, MS, Brasil. E-mail: flaviabotanica@gmail.com. *Autor para correspondência. 
insuficiente, hipocloridria e motilidade inadequada (GONZALES CALVIN et al., 1998). Essas concreções são formadas na luz do trato digestivo, geralmente no estômago, ou em continuidade ao intestino delgado, ou, ainda, fragmentam-se em múltiplas massas detectáveis em qualquer segmento intestinal (JESUS \& NOVELLI, 2005).

Com frequência, os bezoares de concreções fibrosas, encontrados no trato gastrointestinal dos ruminantes, ocasionam transtornos digestivos, como obstruções intestinais em caprinos, ovinos e ruminantes selvagens, como consequência da ingestão de alimentação com elevado conteúdo em fibra de baixa qualidade presentes em plantas nativas (DIRKSEN \& DOLL, 2005).

O consórcio entre gramíneas e leguminosas tem sido bem aceito por pecuaristas das regiões produtivas do Cerrado, pois aumenta a produtividade das pastagens, resultando em alta disponibilidade alimentar ao rebanho, principalmente na época seca do ano (BARCELLOS et al., 2001; PACIULLO et al., 2003). O emprego de leguminosas em consórcio com gramíneas melhora o solo deficiente em nutrientes, devido à fixação e ciclagem de nitrogênio (CADISH et al., 1994). Além disso, as leguminosas, como o Stylosanthes guianensis cv. 'Mineirão', melhoram o valor nutritivo da forragem disponível nas pastagens consorciadas, devido seus maiores teores de proteína bruta (PACIULLO et al., 2003; BARCELLOS et al., 2008). Resultados insatisfatórios, no entanto, podem ocorrer no emprego destas pastagens consorciadas, em relação ao consumo e ganho de peso do animal, principalmente no que se refere à baixa palatabilidade das leguminosas (PEREIRA et al., 1992), bem como a utilização destas, em proporções distintas daquelas recomendadas (UBIALI et al., 2013).

O gênero Stylosanthes SW. é tropical, predomina na América do Sul e Central (LEWIS et al., 2005), com 63\% das espécies ocorrendo no Brasil. Há riqueza de representantes nos estados de Mato Grosso do Sul, Minas Gerais e Paraná (FERREIRA \& SOUZA COSTA, 1979; SOUZA COSTA \& FERREIRA, 1984), e o sucesso reprodutivo desse gênero dá-se à resistência a solos pouco férteis e secos, e à tolerância ao pisoteio pelo rebanho (GARDENER, 1984).

Em Mato Grosso do Sul e nas demais áreas de Cerrado, três espécies do gênero Stylosanthes têm potencial para utilização em consórcios com gramíneas, tendo sido desenvolvidas variedades para uso nos solos desse bioma, entre elas S. guianensis cv. 'Mineirão', S. macrocephala (Pioneiro) e a mistura física do $S$. macrocephala e $S$. capitata, conhecida como Estilosantes Campo Grande (KARIA \& ANDRADE, 1996).
As características estruturais de espécies forrageiras estão relacionadas ao potencial agrostológico e palatabilidade para bovinos (SILVA et al., 2005; ALVES DE BRITO \& RODELLA, 2001). Assim, a maior proporcionalidade de tecidos macios, a exemplo do parênquima, em relação a tecidos mais resistentes, como esclerênquima, e a presença de cristais, podem afetar a digestabilidade da forrageira (ALVES DE BRITO \& RODELLA, 2001), o que pode estar associado à maior ou menor potencialidade de formação de fitobezoares. A composição dos fitobezoares no rebanho bovino já é discutida desde a década de 90 (MORAES et al., 1993) e ainda é incerta, sendo muitas vezes indicado no meio produtivo como estruturas que contêm pelos de animais e tricomas de plantas.

Considerando a escassez de trabalhos elucidativos sobre a estrutura dos fitobezoares bovinos, este trabalho avalia a composição dos fitobezoares coletados de animais submetidos à dieta do consórcio de Stylosanthes com Brachiaria decubens Stapf (Poaceae). Também é descrita a anatomia foliar comparativa das três espécies nativas e de uma cultivar de Stylosanthes, sendo quantificada a proporção de fibras das espécies.

\section{MATERIAL E MÉTODOS}

As espécies Stylosanthes capitata Vogel, S. guianensis var. vulgaris M.B. Ferreira \& Sousa Costa cv. 'Mineirão' e S. macrocephala M. B. Ferreira $\&$ S. Costa foram coletadas no banco de germoplasma de leguminosas forrageiras da Embrapa Gado de Corte, em Campo Grande, MS, Brasil. A espécie Stylosanthes guianensis (Aubl.) Sw. foi coletada na Reserva Particular do Patrimônio Natural RPPM - da Universidade Federal de Mato Grosso do Sul, Campo Grande, MS, Brasil. Após coleta, o material foi fixado em FAA 50\% (formaldeído, ácido acético glacial, etanol $50 \%$, na proporção $1: 1: 18$ ), por $24 \mathrm{~h}$, lavado em água corrente, desidratado em série etanólica até etanol 70\%, e conservado nesse líquido conforme a metodologia usual em anatomia vegetal (JOHANSEN, 1940).

Os cinco fitobezoares bovinos, cedidos pela Embrapa Gado de Corte, foram obtidos de animais mortos por obstrução intestinal, alimentados em pastagens consorciadas de Stylosanthes e Brachiaria. Os constituintes dos fitobezoares foram separados com auxílio de pinças e agulhas e analisados em estereomicroscópio. As estruturas fibrosas foram separadas e submetidas à maceração com solução de 
FRANKLIN (1946), mantidas por 24 horas em estufa aquecida a $60^{\circ} \mathrm{C}$. Após lavagem abundante em água destilada, o material foi corado com safranina $1 \%$ aquosa e montado em lâminas semipermanentes em glicerina 50\% para avaliação em microscopia de luz.

As lâminas semipermanentes foram confeccionadas a partir de cortes à mão livre com o auxílio de lâmina de aço. $\mathrm{O}$ material seccionado foi diafanizado em hipoclorito de sódio, lavado em água destilada e corado em azul de astra e safranina, ambas $1 \%$ em água, na proporção de 9:1, e montado em lâmina com glicerina $50 \%$. Secções transversais dos folíolos também foram obtidas de material infiltrado em historesina Leica ${ }^{\circledR}$, cortado em micrótomo rotativo $10 \mu \mathrm{m}$, corado em azul de toluidina e confeccionadas lâminas permanentes em Entellan ${ }^{\circledR}$.

Para destacar a epiderme, fragmentos dos folíolos foram colocados em solução de FRANKLIN (1946) e mantidos em estufa aquecida a $60^{\circ} \mathrm{C}$ por 24 horas e, posteriormente, coradas em azul de astra e safranina etanólicos e montados em lâminas semipermanentes em glicerina 50\%.

Para identificação de compostos da parede, citoplasma ou vacúolo, foram realizados cortes à mão livre e aplicados testes histoquímicos com floroglucinol clorídrico para identificação de lignina (SASS, 1951); sudan III, para cutina e substâncias de natureza lipídica (SASS, 1951); cloreto férrico para compostos fenólicos (JOHANSEN, 1940) e vermelho de rutênio para identificação de substâncias pécticas (STRASBURGER, 1924).

Para identificação dos cristais nos folíolos das quatro espécies de Stylosanthes e das fibras do fitobezoar, o material foi incinerado em mufla: duas folhas de cada espécie e aproximadamente, a mesma quantidade de fitobezoar, com taxa de aquecimento de $10^{\circ} \mathrm{C}$ por minuto, permanecendo por duas horas a $100^{\circ} \mathrm{C}$ para secagem e, após essa etapa, com mesma taxa de aquecimento, permaneceram por duas horas a $800^{\circ} \mathrm{C}$. Para confirmação da composição dos cristais com o material incinerado, foi realizado teste de dissolução de cristais com ácido clorídrico 50\% para oxalato de cálcio (JOHANSEN, 1940).

A análise e documentação em microscopia de luz foram realizadas em microscópio DM 5500B, acoplado em sistema de captura de imagem Leica DFC495. As mensurações dos diâmetros das fibras foram conduzidas no programa Image J. Para análise da superfície foliar, amostras fixadas de $\boldsymbol{S}$. guianensis e $\boldsymbol{S}$. guianensis cv. 'Mineirão' foram desidratadas em série etanólica crescente, até etanol absoluto, submetidas ao ponto crítico do $\mathrm{CO}_{2}$, montadas em suportes apropriados e recobertas com fina camada de ouro antes da observação. As eletromicrografias da epiderme das espécies foram obtidas por meio do Microscópio Eletrônico de Varredura JEOL JSM-6380LV.

\section{RESULTADOS}

Os bezoares analisados eram constituídos, em grande parte, por "cordões" de fibras vegetais (Figura 1A), que se apresentaram agrupadas em feixes de tecido esclerenquimático de paredes fortemente lignificadas (Figura 1B); após a maceração foi possível observar as fibras libriformes (Figura 1C) e as sobras da bainha parenquimática portando cristais (Figura 1D). Os feixes de fibras presentes nos fitobezoares monstraram-se idênticos aos feixes vasculares encontrados nos folíolos das espécies de Stylosanthes analisadas (Figura 1 E e F).

As folhas de Stylosanthes capitata, $S$. guianensis, S. guianensis var. vulgaris cv. 'Mineirão' e $\boldsymbol{S}$. macrocephala eram anfiestomáticas. A epiderme foliolar foi semelhante em todas as espécies, com estômatos do tipo paracítico (Figura 2A, B e C) e células anexas com parede anticlinal sinuosa (Figura 2A e B). Tricomas tectores (Figura 2B e D) ocorreram em ambas as faces do folíolo, destacando-se que somente $S$. macrocephala não possui tricomas na face adaxial (Figura 2A). Além do tricoma tector, $\boldsymbol{S}$. guianensis cv. 'Mineirão' possui tricomas de base dilatada em ambas as faces do folíolo (Figura 2E), não sendo observado esse tipo de variação nos tricomas das demais espécies analisadas. As células epidérmicas apresentaram cristais de oxalato de cálcio, observandose um por célula (Figura 2A, B e C).

$\mathrm{O}$ mesofilo das quatro taxas avaliadas era constituído de parênquima paliçádico e esponjoso (Figura 3A-F), e feixes vasculares aos quais grandes calotas de feixes de fibras lignificadas estavam associados (Figura 3A-F). Idioblastos contendo compostos fenólicos na face abaxial (Figura 3E) e células alongadas, entre as células de parênquima paliçádico, contendo mucilagem (Figura 3F) na face adaxial, foram observados em todas as espécies.

A bainha parenquimática presente nas espécies apresentou cristais de oxalato de cálcio (Figura 3A-D). No interior dessa bainha parenquimática, logo abaixo da região mais próxima ao floema, voltados para a face abaxial, destacam-se feixes de fibras (Figura 3A-D), constituídos por fibras libriformes (Figura 1E e F) fortemente lignificadas (Figura 3A-D). Essas fibras eram totalmente lignificadas, exceção apenas para S. guianensis (Figura 3D) cujas fibras são gelatinosas. Os cordões de fibras de maior porte ocorreram no bordo do folíolo 


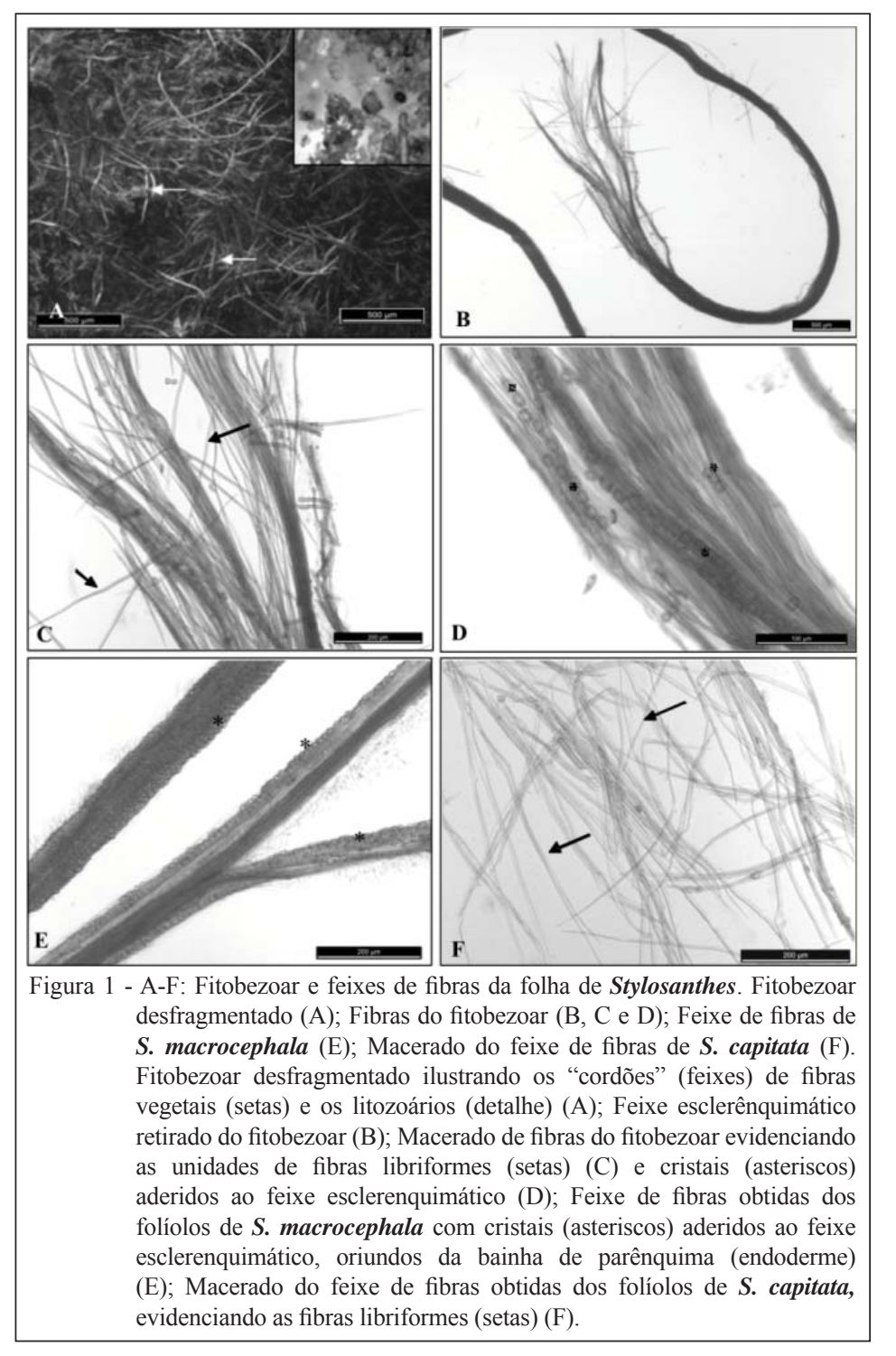

e próximo à nervura mediana, com valores distintos entre as espécies avaliadas, média de $89.129 \mu \mathrm{m}$ para S. capitata, $161.132 \mu \mathrm{m}$ em S. guianensis cv. 'Mineirão', $170.795 \mu \mathrm{m}$ para S. guianensis e $223.804 \mu \mathrm{m}$ para $\boldsymbol{S}$. macrocephala.

\section{DISCUSSÃO}

A composição dos fitobezoares analisados corrobora o descrito por MARTINS et al. (2004), que detectaram litozoários em meio às concreções de fibras vegetais, ao avaliarem casos clínicos de extração de fitobezoar em bovinos. Segundo MARTINS et al. (2004), logo após a extração do fitobezoar do aparelho digestivo do animal, e quando o núcleo do aglomerado é cortado, além de partículas minerais (litozoários) foi observada a presença de um material pegajoso entremeando as fibras vegetais. Nos fitobezoares avaliados nesta pesquisa, não foi detectada substância pegajosa entre as fibras, como citado por MARTINS et al. (2004), devido aos materiais avaliados estarem totalmente desidratados.

A análise anatômica das espécies de Stylosanthes evidenciou a presença de idioblastos com compostos fenólicos e mucilagem em todas as espécies. As características anatômicas observadas para as espécimes avaliadas corroboram as descrições clássicas elaboradas por METCALFE \& CHALK (1950) e SOLEREDER (1908).

Os feixes de esclerênquima com paredes fortemente lignificadas e os idioblastos portando compostos fenólicos e mucilagem são potenciais 


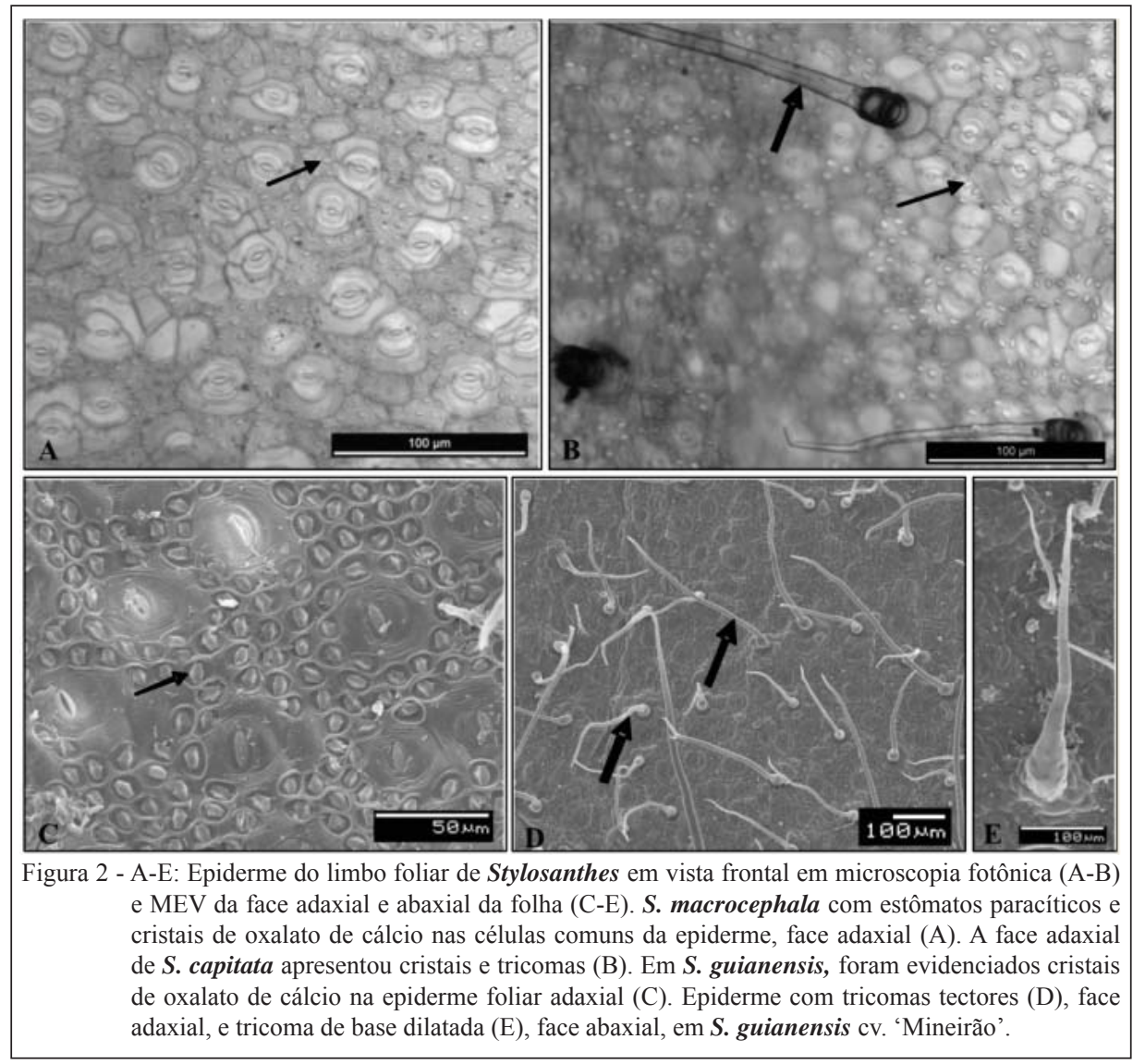

formadores de fitobezoar, quando há excesso no consumo de Stylosanthes na dieta bovina em relação às gramíneas. Alguns autores citam que uma dieta baseada em vegetais com elevada concentração de lignina e compostos secundários, juntamente com a celulose, podem ocasionar a incidência de fitobezoares (BLAM \& LICHTENSTEIN, 2000; ERZURUMLU et al., 2005; ZHANG et al., 2008). Além disso, o excesso no consumo de Stylosanthes e sua predisposição na formação de fitobezoares já foi relatado por UBIALI et al. (2013) em pastagens com predomínio de Stylosanthes sp., o qual pode levar à obstrução intestinal e morte em bovinos.

Considerando que a lignina em excesso diminui a palatabilidade e digestibililidade em bovinos (SILVA et al., 2005; ALVES DE BRITO \& RODELLA, 2001), os resultados quanto ao tamanho do feixe de fibras sugerem que $S$. macrocephala possui menor grau de digestibilidade, comparado com as demais espécies avaliadas.

A forma dos cristais presentes ao redor dos feixes de fibras dos fitobezoares e dos cristais presentes na epiderme e na bainha parenquimática nos folíolos das espécies de Stylosanthes sugere que são cristais de oxalato de cálcio (Figura 1D e E). Por serem estruturas da mesma composição e formato semelhante, também sugerem ser potenciais fomadores dos fitobezoares. SOLEREDER (1908) já descrevia para o gênero Stylosanthes a ocorrência de cristais de oxalato de cálcio e, em trabalhos realizados por JERBA et al. (2006), ele denomina essas estruturas de estegmatas. Entretanto, ASSUMPÇÃO (1978) descreve em seu trabalho para o gênero Stylosanthes a presença de sílica, estrutura não observada no presente trabalho.

\section{CONCLUSÃO}

Os feixes de esclerênquima, os idioblastos com fenóis e mucilagem, além da abundância de cristais de oxalato de cálcio, seja na epiderme dos folíolos ou na bainha parenquimática dos feixes vasculares de Stylosanthes avaliadas, podem ser potenciais formadores de fitobezoares em bovinos, quando há excesso de consumo das espécies avaliadas. 


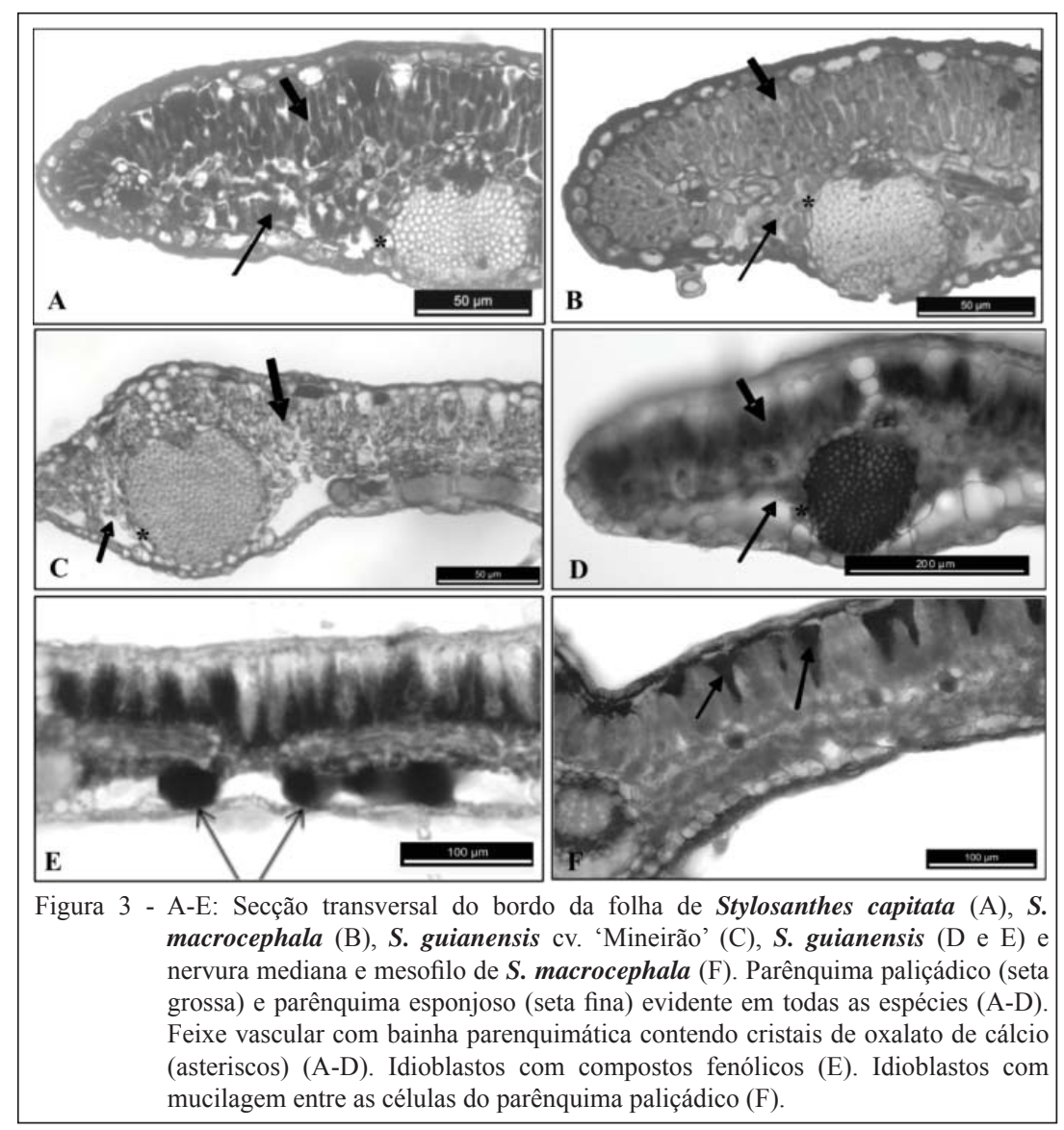

\section{AGRADECIMENTOS}

Ao pesquisador da Empresa Brasileira de Pesquisa Agropecuária (Embrapa) - Gado de Corte, Celso Fernandes Dornelas, por disponibilizar o material botânico e os fitobezoares para a realização desta pesquisa; ao técnico Luiz Felipe Plaça e ao Laboratório de Microscopia eletrônica de varredura da Universidade Federal do Mato Grosso do Sul (UFMS), pela assistência prestada na confecção das eletromicrografias.

\section{REFERÊNCIAS}

ALVES DE BRITO, C.J.F.A.; RODELLA, R.A. Breve histórico das relações entre anatomia vegetal e qualidade de gramíneas forrageiras com ênfase para o gênero Brachiaria. Revista de Agricultura, v.76, n.1, p.19-36, 2001.

ASSUMPÇÃO, W.R.C. O gênero Stylosanthes em Minas Gerais (anatomia). Oréades, v.5, p.97-115, 1978.

BARCELlOS, A.O. et al. Potencial e uso de leguminosas forrageiras dos gêneros Stylosanthes, Arachis e Leucaena. In: SIMPÓSIO SOBRE MANEJO DA PASTAGEM, 2001, Piracicaba, SP. Anais... Piracicaba: FEALQ, 2001. p.365-426.

BARCELLOS, A.O. et al. Sustentabilidade da produção animal baseada em pastagens consorciadas e no emprego de leguminosas exclusivas, na forma de banco de proteína, nos trópicos brasileiros. Revista Brasileira de Zootecnia, v.37, supl. esp., p.51-67, 2008.
Disponível em: $\quad<\mathrm{http}: / /$ www.scielo.br/scielo.php?script=sci_ arttext\&pid $=$ S 1516-35982008001300008\&lng $=$ en\&nrm $=$ iso $\&$ tlng=pt $>$. Acesso em: 21 mar. 2013. doi: 10.1590/S151635982008001300008 .

BLAM, M.E.; LICHTENSTEIN, G.R. A new endoscopic technique for the removal of gastric phytobezoar. Gastrointestinal Endoscopy. 52ed., p.404-408, 2000.

CADISH, G. et al. Nitrogen cycling in a pure grass pasture and a grass-legume ixture on a red latosol in Brazil. Tropical Grasslands, v.28, n.1, p.43-52, 1994.

DIRKSEN, G.; DOLL, K. Obstrucción interna del intestino, íleo por obturación. In: DIRKSEN, G. et al. Medicina interna y cirugía del bovino. 4.ed. Buenos Aires: Inter.-Médica, 2005. V.1, p.484-485.

ERZURUMLU, K. et al. Gastrointestinal bezoars: a retrospective analysis of 34 cases. World Journal of Gastroenterology, v.11, n.12, p.1813-1817, 2005.

FRANKLIN, G.L. A rapid method of softening wood for microtome sectioning. Australian Journal of Botany, v.33, p.393-408, 1946.

FERREIRA, M.B.; SOUZA COSTA, N.M. de S. O Gênero Stylosanthes no Brasil. Belo Horizonte: Empresa de Pesquisa Agropecuária de Minas Gerais (EPAMIG), 1979. 107p.

Ciência Rural, v.43, n.11, nov, 2013. 
GARDENER, C.J. The dynamics of Stylosanthes pasture. In: STACE, H.M.; EDYE, L.A. (Ed.). The biology and agronomy of Stylosanthes. Centercourt: Academic, 1984. p.333-357.

GONZALEZ CALVIN, J.L. et al. Tratamiento médico del fitobezoar gastrico. Revista Española de Enfermedades Digestivas, v.74, p.215-218, 1998.

JERBA, V.F. et al. Relação entre número de estegmata na epiderme foliar e intensidade de antracnose em Stylosanthes spp. Pesquisa Agropecuária Brasileira, v.41, n.1, p.175-178, 2006. Disponível em: $\quad<\mathrm{http} / /$ www.scielo.br/scielo.php?script=sci arttext\&pid=S0100-204X2006000100025\&lng $=$ en\&nrm $=$ is o\&tlng=pt $>$. Acesso em: 21 mar. 2013. doi: 10.1590/S0100204X2006000100025.

JESUS, L.E.; NOVELLI, R.J.M. Trichobezoar. Revista do Colégio Brasileiro de Cirurgiões, v.32, n.3, p.157160, 2005. Disponível em: <http://www.scielo.br/scielo. php? script=sciarttext\&pid=S0100-69912005000300012\&lng=en $\&$ nrm=iso\&tlng=pt>. Acesso em: 21 mar. 2013. doi: 10.1590/ S0100-69912005000300012.

JOHANSEN, D.A. Plant microtechnique. New York: McGrawHill, 1940. 523p.

KARIA, C.T.; ANDRADE, R.P. Caracterização e avaliação preliminar de espécies forrageiras no Centro de Pesquisa Agropecuária dos Cerrados. In: Simpósio sobre Cerrados, 8., 1996, Brasília, DF. Anais... Planaltina: Embrapa-CPAC, 1996. p.471-475.

LEWIS, G. et al. Legumes of the world. Kew: Royal Botanic Gardens, 2005. 577p.

MARTINS, A.M.C.R.P.F. et al. Presença de corpos estranhos no habituais no aparelho digestório dos bovinos. Comunicação cientifica. Arquivos do Instituto Biológico, v.71, n.1, p.83-87, 2004.

METCALFE, C.R.; CHALK, L. Anatomy of the dicotyledons. Oxford: Clarendon, 1950. 500p.

MORAES, R.S. et al. Oclusão intestinal por fitobezoar: relatos de dez casos. Revista Brasileira de Coloproctologia, v.13, n.1, p.501-504, 1993.

PACIULLO, D.S.C. et al. Características produtivas e qualitativas de pastagem de braquiária em monocultivo e consorciada com estilosantes. Pesquisa Agropecuária Brasileira, v.38, n.3, p.421-426, 2003. Disponível em: <http://www.scielo.br/scielo. php?script=sciarttext \&pid=S0100-204X2003000300012\&lng=e $\mathrm{n} \& \mathrm{nrm}=\mathrm{iso} \& \mathrm{tlng}=\mathrm{pt}>$. Acesso em: 21 mar. 2013. doi: 10.1590/ S0100-204X2003000300012.

PEREIRA, J.M. et al. Teor de proteína bruta e digestibilidade in vitro da matéria seca da forragem disponível e da dieta selecionada por bovinos em pastagem de Brachiaria humidicola (Rendle) Schweickt, em monocultivo ou consorciado com leguminosas, submetida a diferentes taxas de lotação. Revista da Sociedade Brasileira de Zootecnia, v.21, n.1, p.104-117, 1992.

POZO, P.; VALOIS, T. Trichobezoar in a 11 years old girl: a case report. Boletín Asociación Médica de Puerto Rico, v.88, p.8-11, 1996.

SASS, J.E. Botanical microtechinique. 2.ed. Ames: The Iowa State College, 1951. 391p.

SILVA, M.L. et al. Inter-relações entre a anatomia vegetal e a produção vegetal. Acta Botanica Brasílica, v.19, n.1, p.183194, 2005. Disponível em: <http://www.scielo.br/scielo. php?script $=$ sci_arttext\&pid=S0102-33062005000100018\&lng $=$ pt\&nrm=iso>. Acesso em: 21 mar. 2013.

SOUZA COSTA, N.M.S.; FERREIRA, M.B. Some Brazilian species of Stylosanthes. In: STACE, H.M.; EDYE, L.A. (Eds.). The biology and agronomy of Stylosanthes. North Ryde, Australia: Academic, 1984. p.23-48

SOLEREDER, H. Systematic anatomy of the dicotyledons. 2.ed. Oxford: Clarendon, 1908. 2v.

STRASBURGER, E. Handbook of practical botany. 8ed. London: Sonneschein, 1924. 533p.

UBIALI, D.G. et al. Obstrução intestinal em bovinos associada ao consumo de Stylosanthes sp. (Fabaceae Papilionoideae). Pesquisa Veterinária Brasileira, v.33, n.2, p.148-154, 2013.

ZHANG, R.L. et al. Huge gastric disopyrobezoar: a case report and review of lituratures. World Journal of Gastroenterology, v.14, p.152-154, 2008. Disponível em: <http://www.wjgnet.com/10079327/14/152.pdf $>$. Acesso em: 21 mar. 2013. doi: 10.3748/ wjg.14.152. 